\title{
SUITABILITY OF BROKEN BOTTLES AS FINE AGGREGATE FOR PRODUCTION OF CONCRETE
}

\author{
S. T. TYAGHER AND J. T. UTSEV
}

(Received 9, November 2011; Revision Accepted 2, March 2012)

\begin{abstract}
The use of broken bottles as partial replacement of river sand for production of concrete was investigated. The grading of the broken bottles and sand fell in zone II. The specific gravity of the bottles was 2.55 and that of sand was 2.65. Sand was replaced with the broken bottles in the proportions of $0 \%, 10 \%, 20 \%, 30 \%, 40 \%$, and $50 \%$ by weight. The mix of $1: 2: 4$ by weight and watercement ratio of 0.45 were used. Cubes of side $150 \mathrm{~mm}$ were cast for each proportion, cured by complete immersion in water and tested for density and strength at the ages of 7,14 and 28 days. The average compressive strength of the cubes was found to increase with curing age but decrease with increase in the proportion of broken bottles in the mix. The proportion of broken bottles to give a minimum strength of $20 \mathrm{~N} / \mathrm{mm}^{2}$ was $30 \%$ at 7 and 14 days, and $40 \%$ at 28 days. The maximum mean compressive strength of $19.0 \mathrm{~N} / \mathrm{mm}^{2}$ was obtained at 28days when sand and broken bottles were used in equal proportions. Density did not appear to have a discernible trend. For structural concrete, the proportion of broken bottles should be limited to $30 \%$ for early strength concrete and $40 \%$ when early strength is not required. For non-structural concrete, proportion greater than $40 \%$ can be used.
\end{abstract}

KEYWORDS: Broken bottles, River sand, Partial replacement, Concrete, Strength.

\section{INTRODUCTION}

Concrete is a composite construction material made up of cement, aggregates (fine and coarse) and water (sometimes with admixtures) in required proportions. Gambhir (2004) considered the hardened concrete as an artificial stone in which the voids of larger particles (coarse aggregate) are filled by the smaller particles (fine aggregate), and the voids of fine particles are filled with cement. He indicated that the key to producing a strong, durable and uniform concrete (high performance concrete) lies in the careful control of its basic components which include cement, aggregates (fine and coarse), water and admixtures.

Neville (2006) defines aggregates as naturally - occurring, inert granular materials such as sand, gravel or crushed stone. According to him, recycled materials and synthetic products have recently been considered and used as aggregates. He classifies aggregate into fine (sand) and coarse (gravel) aggregates.

According to Gambhir (2004), aggregates are generally cheaper than cement and impart greater volume stability and durability to concrete. Aggregates are used in two or more sizes to increase the density of the resulting mix. He pointed out that the most important function of fine aggregate is to assist in producing workability and uniformity in the concrete mixture. Fine aggregate also assists the cement paste to hold the coarse aggregate particles in suspension. This action promotes plasticity in the mixture and prevents the possible segregation of the paste and coarse aggregates.

Murdock et al (1991) indicated that aggregates provide about 75 percent of the body of concrete. If the concrete is to be workable, strong, durable and economical aggregates must be of proper shape (either rounded or approximately cubical), clean, hard, strong and

S. T. Tyagher, Department of Civil Engineering, University of Agriculture, Makurdi, Nigeria.

J. T. Utsev, Department of Civil Engineering, University of Agriculture, Makurdi, Nigeria. 
well-graded.

Sand used for production of concrete is to be ideally river sand. Only in areas at or near the banks of rivers that sand can be obtained cheaply and in great quantities. In other areas, high cost of sand can be experienced because of its scarcity. It is therefore necessary to find substitutes for river sand for production of concrete to reduce cost of concrete construction in such areas.

Broken bottles abound all over the world as waste. Their use will reduce the nuisance they cause to man. It is therefore necessary to conduct researches on broken bottles with the view to finding ways they can be useful to man. This paper is aimed at showing the usefulness of broken bottles as a partial substitute for river sand for production of concrete.

\section{FINE AGGREGATE}

Gambhir (2004) defines fine aggregate as the aggregate most of which passess through a $4.75 \mathrm{~mm}$ sieve. The fine aggregate may be natural sand, crushed stone sand or crushed gravel sand. The Indian Standard (IS: 383 1970 ) divided the fine aggregate into four grading zones namely zones I, II, III, and IV. From grading zone I to IV, the fine aggregate becomes progressively finer. A fine aggregate is considered as belonging to the zone in which its percentage passing the $600 \mu \mathrm{m}$ sieve falls and it is allowed to fall outside the limits fixed for other sieve by not more than a total of 5 percent.

According to Neville (1996), sand falling into any zone can generally be used in concrete, although under some circumstances, the suitability of a given sand may depend on the grading and shape of the coarse aggregate. The suitability of fine sand of zone IV for use in reinforced concrete has to be tested. He stated further that fine sand can be utilized with success if proportioned correctly. This is of considerable economic importance in areas where there is a predominance of fine sand. The coarse sand of zone I produces a harsh mix, and a high cement content may be necessary for higher workability. This sand is more suitable for rich mixes or for use in concrete of low workability. Zone II represents a medium sand generally suitable for the standard 1:2 fine to coarse aggregate mix for maximum size of aggregate of $20 \mathrm{~mm}$.

Agbede and Joel (2004) investigated the suitability of quarry dust for use as partial replacement of river sand in production of sandcrete blocks. The results were that the compressive strength of blocks increased with increasing inclusion of quarry dust, while density did not have discernible trend. They concluded that quarry dust should be used as partial replacement for river sand in production of sandcrete blocks when sand is in short supply and very expensive. They cautioned that the blocks should be properly cured for 28days, and clean water must be used in mixing the materials.

\section{BROKEN BOTTLES}

According to Otokpa (2008), broken bottles are hard, non-crystalline and non-plastic materials that are clear and transparent with thickness varying from $0.5 \mathrm{~mm}$ to $0.8 \mathrm{~mm}$. The shape of the broken bottles depends on the shape of its parent bottle.

The study conducted by him indicated that the density and compressive strength developed in concrete produced with broken bottles partially replacing gravel (coarse aggregate) decreased with increase in proportion of the broken bottles. The concrete mix ratio was 1: 1.5:3 (i.e. cement: sand: gravel/broken bottles) by weight with water - cement ratio of 0.45 . The ratios of broken bottles to gravel used were $0: 1$, $1: 0,1: 1,1: 3$ and $3: 1$ by weight. $\mathrm{He}$ recommended that broken bottle concrete should be used for construction of farm house pavement and drainage flooring where gravel would be in short supply.

\section{MATERIALS AND METHOD}

Materials used for the study included ordinary Portland cement, crushed igneous rock, broken bottles, river sand and water. The broken bottles were washed to remove impurities. They were then pounded into smaller sizes using pestle and mortar. The crushed rock, pounded broken bottles and sand were sieved. The sand and crushed bottles were found to fall in zone II, the ideal zone for production of concrete (Neville, 2006). The specific gravity of crushed rock and sand was found to be 2.65; and that of the broken bottles was 2.55 .

The mix proportion adopted was 1:2:4 and water cement ratio of 0.45 . The batching of the constituent materials was by weight. The broken bottles substituted sand in the mixes by $0 \%, 10 \%, 20 \%, 30 \%, 40 \%$, and $50 \%$ by weight.

The batched quantities were thoroughly mixed on a neat platform using a shovel. Two step mixing method was adopted (Tyagher, 2008). Cement, sand (or sand/broken bottles mixture) and water were mixed for 2 minutes and 
coarse aggregate added and mixed for further 2 minutes.

Concrete cubes of side $150 \mathrm{~mm}$ were cast and vibrated for 2 minutes using a vibrating table. The cubes were allowed to set and then

Densisty $\left(\mathrm{kg} / \mathrm{m}^{3}\right)=\frac{\text { Weight of cube }(\mathrm{kg})}{\text { Volume of cube }\left(\mathrm{m}^{3}\right)}$

The compressive strength of the cubes was calculated using the formula:

Compressive strength $\left(\mathrm{N} / \mathrm{mm}^{2}\right)=\underline{\text { Crushing load }(\mathrm{N})}$ Area of cube $\left(\mathrm{mm}^{2}\right)$

Total number of cubes used was 56 . The results were as presented in Tables 1, 2 and 3.

Table 1: Mean density and compressive strength at 7 days

\begin{tabular}{|l|l|l|}
\hline $\begin{array}{l}\text { Mean density } \\
\left(\mathrm{kg} / \mathrm{m}^{3}\right)\end{array}$ & $\begin{array}{l}\text { Mean strength } \\
\left(\mathrm{N} / \mathrm{mm}^{2}\right)\end{array}$ & $\begin{array}{l}\text { Percentage } \\
\text { Bottle }(\%)\end{array}$ \\
\hline 2434 & 26.0 & 0 \\
2464 & 25.2 & 10 \\
2491 & 23.8 & 20 \\
2480 & 21.5 & 30 \\
2394 & 18.0 & 40 \\
2410 & 17.0 & 50 \\
\hline
\end{tabular}

Table 2: Mean density and compressive strength at 14 days

\begin{tabular}{|l|l|l|}
\hline $\begin{array}{l}\text { Mean density } \\
\left(\mathrm{kg} / \mathrm{m}^{3}\right)\end{array}$ & $\begin{array}{l}\text { Mean strength } \\
\left(\mathrm{N} / \mathrm{mm}^{2}\right)\end{array}$ & $\begin{array}{l}\text { Percentage } \\
\text { Bottle }(\%)\end{array}$ \\
\hline 2478 & 28.4 & 0 \\
2510 & 26.8 & 10 \\
2465 & 24.3 & 20 \\
2455 & 22.1 & 30 \\
2416 & 19.7 & 40 \\
2422 & 18.2 & 50 \\
\hline
\end{tabular}

Table 3: Mean density and compressive strength at 28 days

\begin{tabular}{|l|l|l|}
\hline $\begin{array}{l}\text { Mean density } \\
\left(\mathrm{kg} / \mathrm{m}^{3}\right)\end{array}$ & $\begin{array}{l}\text { Mean strength } \\
\left(\mathrm{N} / \mathrm{mm}^{2}\right)\end{array}$ & $\begin{array}{l}\text { Percentage } \\
\text { Bottle }(\%)\end{array}$ \\
\hline 2465 & 30.7 & 0 \\
2441 & 29.0 & 10 \\
2418 & 27.7 & 20 \\
2410 & 23.5 & 30 \\
2414 & 20.5 & 40 \\
2405 & 19.0 & 50 \\
\hline
\end{tabular}




\section{DISCUSSION OF RESULTS}

Tables 1, 2 and 3 indicate that the mean compressive strength of concrete increases with increase in curring age, but decreases with increase in the proportion of broken bottles in the mix. Density does not appear to have a discernible trend.

According to BS 8110 (1997), the minimum strength for structural concrete is $20 \mathrm{~N} / \mathrm{mm}^{2}$. The maximum percentage broken bottles to meet this requirement is $30 \%$ at both 7 and 14 days of curring, and $40 \%$ at 28 days. The maximum mean compressive strength of $19.0 \mathrm{~N} / \mathrm{mm}^{2}$ is obtained when sand and broken bottles are used in equal proportions.

Concrete produced using the proportions of broken bottles up to $50 \%$ can be described as heavy concrete. According to Oyenuga (2001), concrete with density from $1980 \mathrm{~kg} / \mathrm{m}^{3}$ and above is described as heavy concrete.

\section{CONCLUSION AND RECOMMENDATIONS}

From the results of the investigation, it can be concluded that broken bottles are potential materials for the production of workable concrete mixes since their grading falls in zone II (Neville, 2006). If thoroughly washed, well pounded and graded, they can be used effectively for production of structural concrete if their proportion is limited to not more than $40 \%$. For the mix ratio 1:2:4 and water-cement ratio of 0.45 investigated, the proportion of broken bottles be limited to $30 \%$ for early strength concrete and $40 \%$ if early strength is not required. For nonstructural concrete, proportions greater than $40 \%$ can be used. The concrete should be properly cured for 28 days, and clean water used in mixing the ingredients.

\section{REFERENCES}

Agbede, I. O and Joel, M., 2004. Suitability of Quarry Dust as Partial Replacement for Sand in Hollow Blocks Production. Nigerian Journal of Engineering Research and Development, 3, (4): 3337.

BS 8110., 1997. Structural use of concrete. British Standards Institution, London.

Gambhir, M. L., 2004. Concrete Technology (3 ${ }^{\text {rd }}$ ed.). Tata McGraw-Hill Publishing Co. Ltd, New Delhi.

IS: 383 - 1970: Specification for Coarse and Five Aggregates from Natural Sources for Concrete $\left(2^{\text {nd }}\right.$ ed.). Bureau of Indian Standards, New Delhi.

Murdock, L. J., Brook, K. M and Dewar, J. D., 1991. Concrete Materials and Practice. Butter and Trauner Limited, London.

Neville, M. A., 2006. Properties of Concrete. The English Language Book Society and Pitman Publishing, London.

Otokpa, E. O., 2008. Use of Broken Bottles as Coarse Aggregate for Concrete Production. Seminar Paper. Department of Civil Engineering, University of Agriculture, Makurdi.

Oyenuga, V. O., 2001. Reinforced Concrete Design. Asros Limited, Lagos.

Tyagher, S. T., 2004. Improving the Compressive Strength of Concrete Using a Two-Step Mixing Method. Nigerian Journal of Industrial and Systems Studies, 7, (1): 46 -49 . 